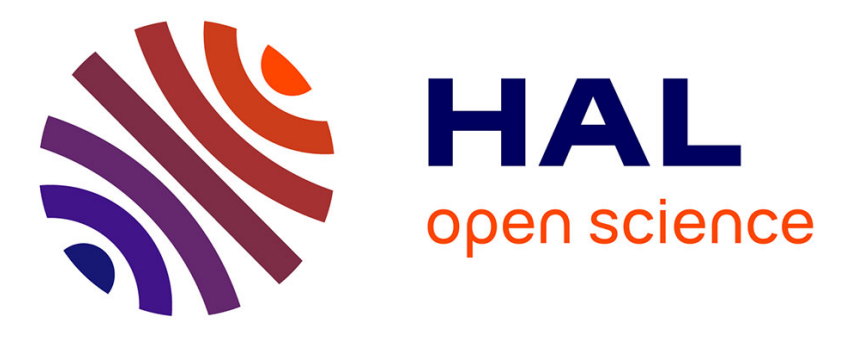

\title{
Guiding Task through Route Description in the MuMMER Project
}

Phani-Teja Singamaneni, Amandine Mayima, Guillaume Sarthou, Yoan

Sallami, Guilhem Buisan, Kathleen Belhassein, Jules Waldhart, Aurélie Clodic

\section{To cite this version:}

Phani-Teja Singamaneni, Amandine Mayima, Guillaume Sarthou, Yoan Sallami, Guilhem Buisan, et al.. Guiding Task through Route Description in the MuMMER Project. HRI '20: ACM/IEEE International Conference on Human-Robot Interaction, Mar 2020, Cambridge, United Kingdom. pp.643-643, 10.1145/3371382.3378398 . hal-02542554

\section{HAL Id: hal-02542554 \\ https://hal.laas.fr/hal-02542554}

Submitted on 17 Apr 2020

HAL is a multi-disciplinary open access archive for the deposit and dissemination of scientific research documents, whether they are published or not. The documents may come from teaching and research institutions in France or abroad, or from public or private research centers.
L'archive ouverte pluridisciplinaire HAL, est destinée au dépôt et à la diffusion de documents scientifiques de niveau recherche, publiés ou non, émanant des établissements d'enseignement et de recherche français ou étrangers, des laboratoires publics ou privés. 


\title{
Guiding Task through Route Description in the MuMMER Project
}

\author{
Phani-Teja Singamaneni, Amandine Mayima, Guillaume Sarthou, Yoan Sallami, Guilhem Buisan, \\ Kathleen Belhassein, Jules Waldhart, Aurélie Clodic \\ firstname.name@laas.fr \\ LAAS-CNRS, Université de Toulouse, CNRS, Toulouse, France
}

\begin{abstract}
The EU-funded MuMMER [1] project (http://mummer-project.eu/) has developed a socially intelligent robot to interact with the general public in open spaces. One of the core tasks for the robot is to guide the visitors to specific locations in the mall. The primary MuMMER deployment location is Ideapark, a large shopping mall in Lempäälä, Finland. The MuMMER robot system has been taken to the shopping mall several times for short-term co-design activities with the mall customers and retailers [2]; the full robot system has been deployed for short periods in the mall in September 2018, May 2019, and June 2019, and has been installed for a long-term, three-month deployment as of September 2019.
\end{abstract}

\section{Description}

Different components allowing the execution of the robot guidance task are explained below. Route computing and route verbalization: The entire description of the route, from the search for the best route to get to the final destination to the verbalization of this route, is based on the Semantic Spatial Representation [6]. Geometric reasoning: It uses Underworlds [5], a lightweight framework for cascading spatio-temporal situation assessment in robotics. It represents the environment as real-time distributed data structures, containing scene graph (for representation of 3D geometries). Based on a 3D model of the mall, it maintains what the robot knows about the scene as well as the estimation of the human's beliefs about the scene. Motion planning: The navigation of the robot is implemented using the ROS navigation stack, with navfn global planner and a modified local planner that accommodates humans into planning, inspired from [3], called Social TEB. SVP planner: The purpose of the SVP (Shared Visual Perspective) planner [7] is to try to find a position where the human will have to go to observe an element of the environment such as a passage, a staircase or a store. To do this, a visibility grid is computed for each possible landmark. Having determined a good position for the human, the planer also allows determining the good position for the robot so as to have a human-robot-landmark conformation allowing both to point the landmark and to look at the human. Supervision and Evaluation of the Quality of Interaction: A supervision system handles the execution. Throughout the task, the robot supervises the execution and, depending on what goes wrong, the robot has multiple possible responses. It is able to handle nominal scenarios of route

Permission to make digital or hard copies of part or all of this work for personal or classroom use is granted without fee provided that copies are not made or distributed for profit or commercial advantage and that copies bear this notice and the full citation on the first page. Copyrights for third-party components of this work must be honored. For all other uses, contact the owner/author(s).

HRI '20 Companion, March 23-26, 2020, Cambridge, United Kingdom

(C) 2020 Copyright held by the owner/author(s).

ACM ISBN 978-1-4503-7057-8/20/03.

https://doi.org/10.1145/3371382.3378398 guidance while being able to take into account contingencies such as the human lack of visibility of the direction. While interacting with people, it evaluates in real-time the quality of the interaction at three different levels which are the interaction session, the task and the action levels as described in [4].

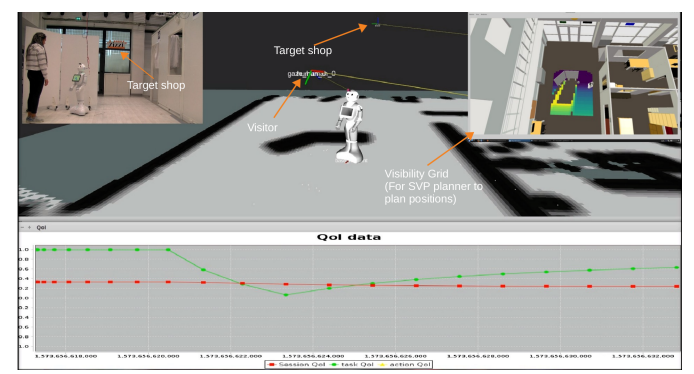

Figure 1: Pepper interacting with a customer

\section{ACKNOWLEDGMENTS}

Thanks to the MuMMER team : Mary Ellen Foster, Bart Craenen, Amol Deshmukh, Oliver Lemon, Emanuele Bastianelli, Christian Dondrup, Ioannis Papaioannou, Andrea Vanzo, Jean-Marc Odobez, Olivier Can, Yuanzhouhan Cao, Weipeng He, Angel Mart, Petr Motlicek, Rémy Siegfried, Alexandre Mazel, Maxime Caniot, Marketta Niemel, Päivi Heikkil, Hanna Lammi, Antti Tammela, Rachid Alami. This work has been supported by the European Union's Horizon 2020 research and innovation program under grant agreement No. 688147 (MuMMER project).

\section{REFERENCES}

[1] Mary Ellen Foster, Rachid Alami, Olli Gestranius, Oliver Lemon, Marketta Niemelä, Jean-Marc Odobez, and Amit Kumar Pandey. 2016. The MuMMER Project: Engaging Human-Robot Interaction in Real-World Public Spaces. In Social Robotics. Springer International Publishing, Cham, 753-763.

[2] Päivi Heikkilä, Marketta Niemelä, Kathleen Belhassein, Guillaume Sarthou, Anti Tammela, Aurélie Clodic, and Rachid Alami. 2019. Should a robot guide like a human? A qualitative four-phase study of a shopping mall robot. In International Conference on Social Robotics (ICSR).

[3] Harmish Khambhaita and Rachid Alami. 2017. Viewing Robot Navigation in Human Environment as a Cooperative Activity. In International Symposium on Robotics Research (ISSR 2017). Puerto Varas, Chile, 18p. https://hal.laas.fr/hal01572555

[4] Amandine Mayima, Aurélie Clodic, and Rachid Alami. 2019. Evaluation of the Quality of Interaction from the robot point of view in Human-Robot Interactions. In 1st Edition of Quality of Interaction in Socially Assistive Robots (QISAR) Workshop. Madrid, Spain. https://hal.laas.fr/hal-02403081

[5] Yoan Sallami, Séverin Lemaignan, Aurélie Clodic, and Rachid Alami. 2019. Simulation-based physics reasoning for consistent scene estimation in an HRI context. In IEEE/RSf International Conference on Intelligent Robots and Systems (IROS 2019). Macau, China. To appear.

[6] Guillaume Sarthou, Rachid Alami, and Aurélie Clodic. 2019. Semantic Spatial Representation: a unique representation of an environment based on an ontology for robotic applications. In SpLU-RoboNLP 2019. Minneapolis, United States, 50 60. https://hal.archives- ouvertes.fr/hal-02177140

[7] Jules Waldhart, Aurélie Clodic, and Rachid Alami. 2019. Reasoning on Shared Visual Perspective to Improve Route Directions. In 2019 28th IEEE International Conference on Robot \& Human Interactive Communication. New Delhi, India. https: //hal.archives-ouvertes.fr/hal-02283904 